\title{
A transapical-to-aorta double lumen cannula-based neonate left ventricular assist device efficiently unloads the left ventricle in neonate lambs
}

Cheng Zhou, MD, PhD, a,b Dongfang Wang, MD, PhD, ${ }^{\text {a }}$ Cherry Ballard-Croft, $\mathrm{PhD},{ }^{\mathrm{a}}$

Guangfeng Zhao, PhD, ${ }^{\mathrm{c}}$ Hassan K. Reda, MD, ${ }^{\mathrm{a}}$ Stephen Topaz, BS, ${ }^{\mathrm{c}}$ and Joseph Zwischenberger, $\mathrm{MD}^{\mathrm{a}}$

\section{ABSTRACT}

Objective: We are developing a transapical-to-aorta double lumen cannula (TAA DLC) for a less-invasive/more dependable neonatal left ventricular assist device.

Methods: The 18-Fr TAA DLC prototypes were bench tested and evaluated for 6 hours in neonate lambs $(\mathrm{n}=6,7.7-10 \mathrm{~kg})$. The cardiac apex was exposed through a left anterolateral thoracotomy through the sixth intercostal space. The TAA DLC was inserted through a mattress stitch on apex, passing LV-aortic valve, into the ascending aorta with insertion/deployment guided by pressure waveform. The DLC was connected to blood pump. Cardiac output and aortic root blood flow were measured with perivascular flow sensors. Activated clotting time was maintained at 180-250 seconds.

Results: The DLC pumped up to $1.8 \mathrm{~L} / \mathrm{min}$ flow against $63 \mathrm{~mm} \mathrm{Hg}$ drainage pressure and $145 \mathrm{~mm} \mathrm{Hg}$ infusion pressure in bench testing. In all lambs, the DLC was inserted/deployed properly within 1 minute on the first attempt. Pumping flow was maintained at 1.2-1.3 L/min. Systolic arterial pressure decreased and diastolic arterial pressure/mean arterial pressure increased, indicating decreased afterload and increased perfusion pressure. Left ventricular end-diastolic pressure decreased from $13 \pm 1 \mathrm{~mm} \mathrm{Hg}$ to $6 \pm 2 \mathrm{~mm} \mathrm{Hg}$, indicating decreased preload. Aortic root backward flow was $2.4 \% \pm 0.6 \%$ without DLC and $3.5 \% \pm 0.8 \%$ of cardiac output with DLC, indicating no significant DLC-induced aortic valve regurgitation. After 6 hours, free hemoglobin was $<5 \mathrm{mg} / \mathrm{dL}$ with hemoglobin/ platelets unchanged. No significant thrombus was found in pumps/DLCs. No trauma was found in LV, aortic valve, and aorta.

Conclusions: Our TAA DLC-based neonate left ventricular assist device efficiently unloaded the LV in lambs. (J Thorac Cardiovasc Surg 2017;153:175-82)

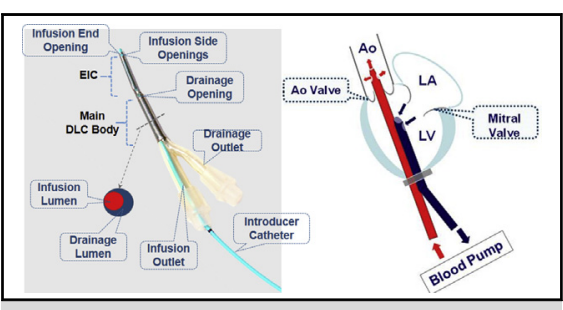

Transapical-to-aorta double lumen cannula inserted from apex into left ventricle-aorta for a less-invasive and more reliable left ventricular assist device.

\section{Central Message}

A transapical-to-aorta double lumen cannulabased neonate left ventricular assist device is easily implanted and efficiently unloads the left ventricle in neonate lambs.

\section{Perspective}

Pediatric pump installation in neonates is challenging. Our transapical-to-aorta double lumen cannula for less-invasive/more dependable neonatal left ventricular assist device is inserted from apex though left ventricle (LV)-aortic valve into the ascending aorta. Coupled with a blood pump, the double lumen cannula withdraws blood from the LV and delivers blood into the aorta, unloading the LV. This transapical-to-aorta double lumen cannulabased neonate left ventricular assist device efficiently unloaded the LV in neonate lambs.

See Editorial Commentary page 183

\footnotetext{
From the a Department of Cardiothoracic Surgery, University of Kentucky, Lexington, $\mathrm{Ky}$; ${ }^{\mathrm{b}}$ Department of Cardiovascular Surgery, Union Hospital, Tongji Medical College, Huazhong University of Science and Technology, Wuhan, China; and ${ }^{\mathrm{c}} \mathrm{W}-\mathrm{Z}$ Biotech, LLC, Lexington, Ky.

This work was supported by National Institutes of Health R43HL120370-01A1

Read at the 96th Annual Meeting of The American Association for Thoracic Surgery, Baltimore, Maryland, May 14-18, 2016.

Received for publication April 11, 2016; revisions received Aug 2, 2016; accepted for publication Aug 11, 2016; available ahead of print Sept 28, 2016.

Address for reprints: Dongfang Wang, MD, PhD, Department of Surgery, University of Kentucky College of Medicine, 800 Rose St, MN321, Lexington, KY 405360298 (E-mail: dnwang2@email.uky.edu).

$0022-5223 / \$ 36.00$

Copyright (c) 2016 by The American Association for Thoracic Surgery

http://dx.doi.org/10.1016/j.jtcvs.2016.08.041
}

Left ventricular assist devices (LVADs) have been applied successfully in adult patients with heart failure. However, the application of LVAD in neonates is limited by the

Scanning this QR code will take you to a video for the article. To view the AATS 2016 Webcast, see the URL next to the video thumbnail. 


$$
\begin{aligned}
& \text { Abbreviations and Acronyms } \\
& \begin{array}{ll}
\mathrm{ABP} & =\text { arterial blood pressure } \\
\mathrm{CO} & =\text { cardiac output } \\
\mathrm{DLC} & =\text { double lumen cannula } \\
\mathrm{ECMO} & =\text { extracorporeal membrane oxygenation } \\
\mathrm{EIC} & =\text { extension infusion cannula } \\
\mathrm{LVAD} & =\text { left ventricular assist device } \\
\mathrm{LV} & =\text { left ventricle } \\
\mathrm{mABP} & =\text { mean arterial blood pressure } \\
\mathrm{PA} & =\text { pulmonary artery } \\
\mathrm{TAA} & =\text { transapical to aorta } \\
\mathrm{VA} & =\text { venoarterial } \\
\mathrm{VAD} & =\text { ventricular assist device }
\end{array}
\end{aligned}
$$

very few choices of LVADs specific for the neonate patient. Venoarterial extracorporeal membrane oxygenation (VA ECMO) is the most common technology for mechanical circulatory support in neonates, providing biventricular support and total gas exchange. ${ }^{1}$ However, VA ECMO (1) is complicated and bulky, requiring high-level anticoagulation; (2) requires continuous sedation or even paralysis with intubation/mechanical ventilation; and (3) occasionally does not fully unload the left ventricle (LV). By contrast, a LVAD circuit lacks a gas exchanger, reduces trauma to blood elements, and decreases the need for anticoagulation. The EXCOR (Berlin Heart GmbH, Berlin, Germany) is the only ventricular assist device (VAD) approved by the Food and Drug Administration available for neonates on the market. ${ }^{2-5}$

Several new pediatric VAD pumps designed for infants and neonates are under development (Jarvik child/infant VAD, PediPump, and PediaFlow). ${ }^{6-9}$ Although these pumps are very small, it is still challenging to implant them into the small neonate body. ${ }^{10-12}$ The neonate's mediastinal cavity is very small and easily leads to conduit kinking/heart compression, which may prevent chest closure. The neonate's open chest requires continuous sedation/anesthesia and is associated with a greater incidence of bleeding/ infection, which makes extubation, mobilization, and oral feeding impossible. Furthermore, LVAD implantation in neonates requires sternotomy and cardiopulmonary bypass, which is very invasive. A less-invasive neonate LVAD is needed to avoid sternotomy and cardiopulmonary bypass, allowing chest closure/extubation, eliminating deep sedation requirement, and enabling oral feeding.

Our approach to the development of a neonate LVAD is to use a DLC for 1-site transapical-to-aorta (TAA) cannulation. This double lumen cannula (DLC)-based LVAD will withdraw blood from the LV and deliver it to the aorta, unloading the LV. Compared with the aforementioned implantable LVADs, our DLC-based neonate LVAD omits the outlet graft. This DLC is also much smaller than a traditional LVAD inlet cannula, distinguishing our system by its easy/less-invasive installation and theoretically reliable performance. In this study, we developed a TAA DLC and tested the prototype in neonate lamb. Our result shows easy, less-invasive implantation, reliable 6 hours in vivo performance, and minimal blood trauma.

\section{METHODS AND MATERIALS \\ Design and Fabrication}

The TAA DLC consisted of a main DLC body and an extension infusion cannula (EIC, Figure 1, A). The round-shaped membrane infusion lumen was internally tangent to outer wall of main DLC body, with one end connected to EIC and the other end connected to the infusion connector. The drainage lumen was the crescent-shaped space between the infusion lumen and the outer wall of main DLC body. The drainage opening was located at the junction between the main DLC body and the EIC. When the TAA DLC was deployed properly, the EIC end was in the ascending aorta for blood delivery and the drainage end opening was in LV for blood drainage, thereby unloading LV (Figure $1, B$ ). Side openings were designed in the EIC to guarantee coronary perfusion (Figure 1, $A$ ).

The size of the main DLC body was $18 \mathrm{Fr}$ and the EIC was $13 \mathrm{Fr}$. The whole DLC was made by one-piece molding. The DLC body outer wall and the EIC was polyurethane copolymer with flat, stainless-steel wire reinforcement to prevent kinking and drainage lumen collapse. The introducer was a single-lumen PVC catheter (450 mm length and $3 \mathrm{~mm} \mathrm{OD),} \mathrm{fitting}$ DLC infusion lumen with very smooth transition on the EIC end opening. The introducer catheter tip pressure can be measured continuously through the catheter lumen opening on the tip. This pressure waveform helped to identify the introducer catheter tip location for accurate catheter insertion and deployment, preventing catheter misplacement into the left atrium and subsequent left atrium penetration. The introducer catheter tip was made blunt to avoid heart injury.

\section{Bench Test of TAA DLC Prototype}

A bench test was performed for TAA DLC performance. The mock circuit included a CentriMag pump (Thoratec, Pleasanton, Calif), 18-Fr TAA DLC prototype, and Tygon connection tubing (US Plastic Corp, Lima, Ohio). A room temperature $37 \%$ glycerin solution was used in the circuit to mimic blood viscosity. The DLC outlet and inlet pressures were measured with a hemodynamic monitor (MP-50; Philips Medical Systems, Boeblingen, Germany). Circuit flow was measured with an ultrasonic tubing flow meter (HT110; Transonic, Ithaca, NY). A pressure-flow curve was generated to characterize DLC performance.

\section{In Vivo Neonate Lamb Evaluation}

Neonate lamb preparation. All studies in animals were approved by the University of Kentucky Institutional Animal Care and Use Committee and were conducted in accordance with the Principles of Laboratory Animal Care (National Society of Medical Research) and the "Guide for the Care and Use of Laboratory Animals" (National Institutes of Health publication no. 86-23, revised 1996).

The TAA DLC prototype-based LVAD system was tested in 6 crossbreed neonate lambs (7.7-10 kg, 13-20 days). These neonate lambs were not yet weaned and relied exclusively on mother's milk feeding. After morning feeding, the neonate lamb was immediately transferred from sheep farm to our laboratory for TAA DLC-based LVAD investigation.

Anesthesia and instrumentation. After anesthesia induction with ketamine $(7 \mathrm{mg} / \mathrm{kg})$ and diazepam $(0.5 \mathrm{mg} / \mathrm{kg})$, all sheep were intubated and connected to the anesthesia machine (Narkomed 2B; DRAGER, Telford, Penn). Anesthesia was maintained with $1 \%$ to $3 \%$ isoflurane, titrating a normal range of heart rate and arterial blood 


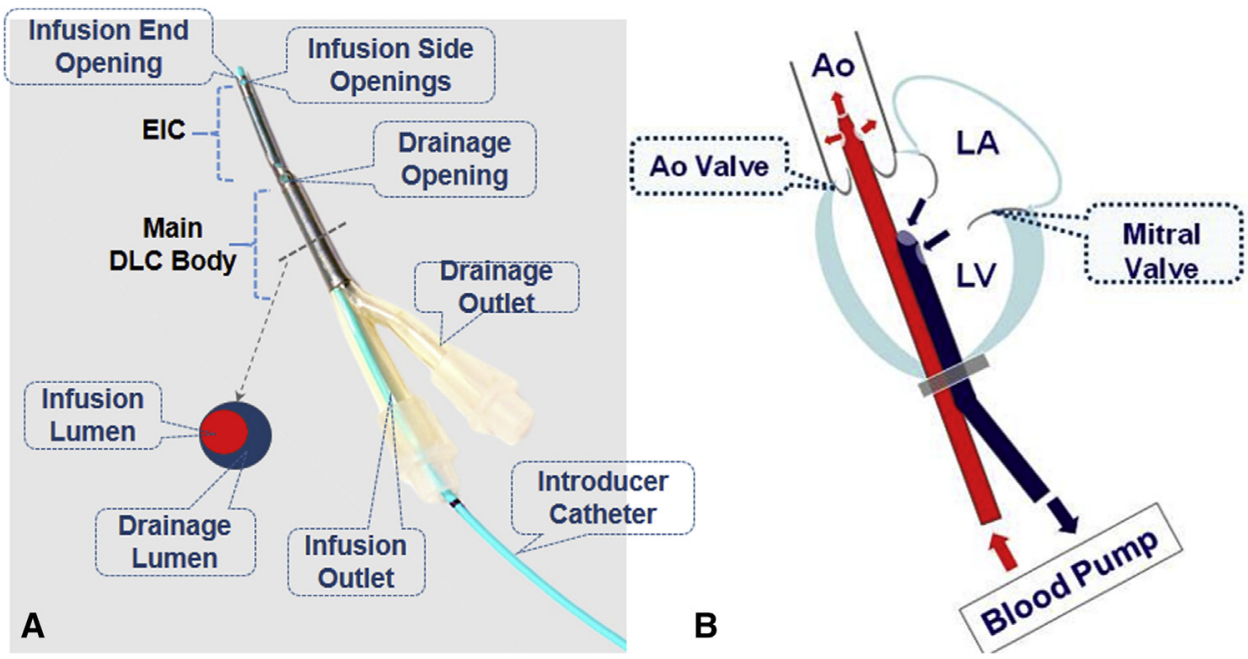

FIGURE 1. Transapical-to-aorta double lumen cannula (TAA DLC) design. A, The TAA design. The TAA DLC consisted of a main body and an extension infusion cannula $(E I C)$. B, TAA DLC deployment from the heart apex and crossing the aortic valve. $D L C$, Double lumen cannula; $A o$, aorta; $L A$, left atrium; $L V$, left ventricle.

pressure (ABP). Two 16 GA Intracath catheters (BD Medical Inc, Sandy, Utah) were placed into the right femoral artery and vein for pressure monitoring, blood sampling, and fluid administration. Another 16 GA Intracath catheter was inserted from the apex into LV for continuous LV pressure monitoring.

The lamb was placed in lateral position with left side up. A $4.5-\mathrm{cm}$ incision was made through the second intercostal space. Pericardiotomy was made to expose the main pulmonary artery (PA) and aortic root. A 12$\mathrm{mm}$ OD perivascular COnfidence flow probe was placed on the main PA and connected to a TS420 perivascular flow meter (Transonic, Ithaca, $\mathrm{NY}$ ) to monitor cardiac output (CO).

DLC insertion and deployment (Video 1). A small left thoracotomy $(3 \mathrm{~cm})$ was made through the sixth intercostal space close to $\mathrm{xi}-$ phoid. Another pericardiotomy was made to expose cardiac apex. A snaring mattress stitch was made on the cardiac apex. A bolus of $150 \mathrm{mg} / \mathrm{kg}$ heparin was administered intravenously to maintain activated clotting time at 180 to 250 seconds. The TAA DLC-based LVAD circuit consisted of an 18-Fr TAA DLC prototype, a CentriMag pump, and a quarter-inch connection tubing. The CentriMag pump and tubing were primed with $50 \mathrm{~mL}$ of heparinized lactated Ringer's solution. The introducer catheter was placed inside the TAA DLC infusion lumen with $8 \mathrm{~cm}$ of introducer catheter extending out of distal infusion end. The introducer catheter was connected to a fluid-filled pressure transducer to measure introducer catheter tip pressure. A Philips MP-50 monitor was used to display the pressure waveform. A $0.5-\mathrm{cm}$ incision was made on the apex inside the mattress stitch. The introducer catheter was inserted from the apex incision into LV and passed the aortic valve. Once the LV pressure waveform turned to the aortic pressure waveform (indicating aortic valve crossing), the introducer catheter was further advanced to set catheter tip 1 to $1.5 \mathrm{~cm}$ beyond the aortic valve (Figure $1, B$ ). After proper positioning, the introducer catheter was held still by surgeon's left hand.

The surgeon held TAA DLC by right hand and slid it along the introducer catheter to the mark on the introducer catheter, indicating that the DLC EIC end was at same level as introducer catheter tip in the ascending aorta (Figure 2). After snaring and tightening the apex mattress stitch to secure the TAA DLC, the surgeon withdrew the introducer catheter, and the TAA DLC was connected to a CentriMag pump. The pump was turned on and pumping flow was increased gradually and maintained at the level of CO for 6 hours (Figure 3).

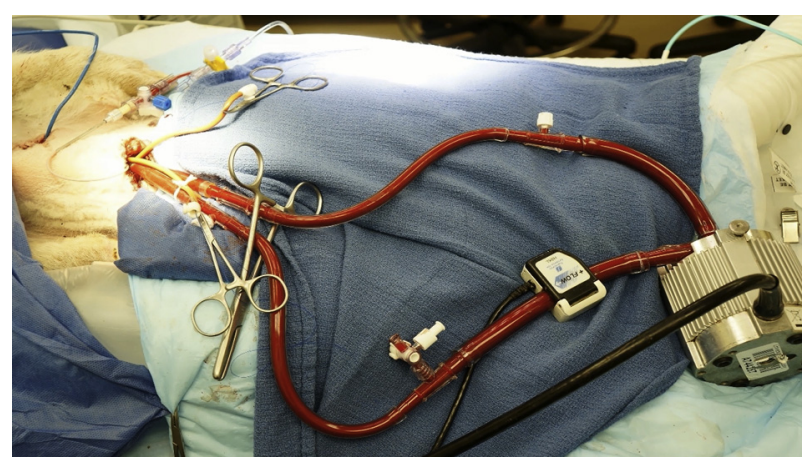

VIDEO 1. Transapical-to-aorta double lumen cannula (TAA DLC)based left ventricular assist device (LVAD) Installation in a neonate lamb. 00:06: An incision through the left second intercostal space to expose the main pulmonary artery (PA); 00:33: Placement of a flow probe on the main PA for cardiac output measurement; 00:53: A left anterolateral thoracotomy at the sixth intercostal space to expose the heart apex; 01:04: Placement of a mattress stitch on the apex; 01:18: Preparation of the TAA DLC by placing the introducer catheter inside the DLC; 01:24: An incision within the mattress stitch to allow TAA DLC insertion; 01:37: Insertion of the TAA DLC introducer catheter through the mattress stitch incision; 02:03: Monitoring of the introducer catheter tip pressure waveform for a location identification. The transition from a left ventricular to an aortic waveform indicates the crossing of the aortic valve; 02:14: The DLC slid over the introducer catheter into aortic root once the position of the introducer catheter tip is confirmed with the waveform; 02:41: Connection of the TAA DLC to the blood pump; 03:05: The LVAD assist begins; 03:20: Echocardiography shows the positions of the aortic valve and the DLC; 03:26: No aortic obstruction and only mild aortic regurgitation around the DLC was observed with echocardiography; 03:36: No mitral valve dysfunction as demonstrated by echocardiography; 03:47: At necropsy, the TAA DLC tip was much smaller than the aortic valve. Video available at: http:// www.jtcvsonline.org/article/S0022-5223(16)31073-X/addons. 


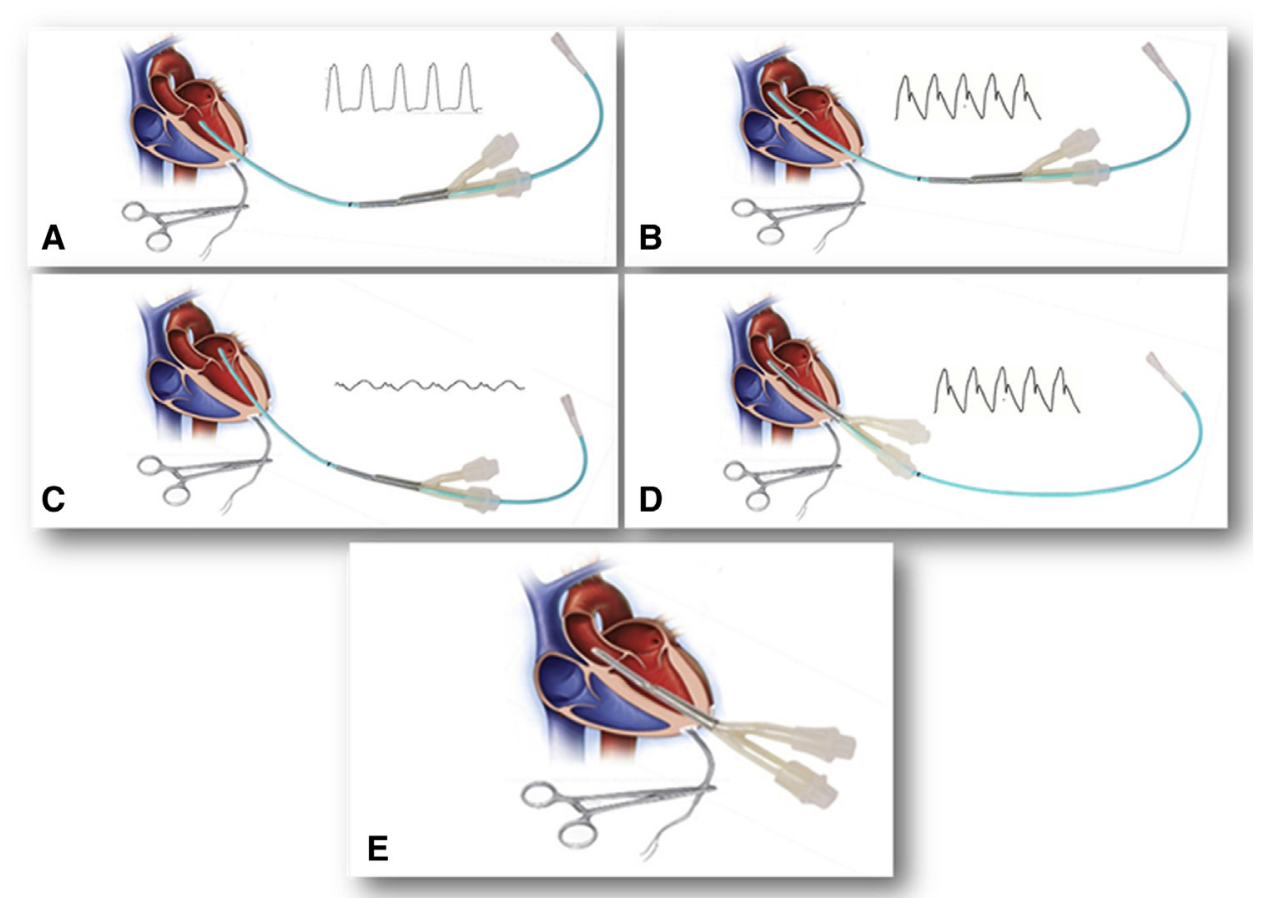

FIGURE 2. Pressure waveform guides insertion and deployment of the transapical-to-aorta double lumen cannula. When left ventricular pressure waveform changes to an aortic pressure waveform, this indicates that the introducer tip has crossed the aortic valve. This allows proper positioning of the extension infusion cannula tip in the ascending aorta. A, Introducer in the left ventricle. B, Introducer in the ascending aorta. C, Introducer in the left ventricle. D, Double lumen cannula deployed accurately. E, Removal of the introducer.

At the sixth hour, pumping was stopped and the circuit was clamped to terminate LVAD testing. The ultrasound flow probe was moved from main PA to ascending aorta to evaluate the aortic valve backflow. The TAA DLC EIC was slowly moved out of aortic valve from aortic root to LV. The aortic root blood flow was measured and recorded continuously.

General animal management during the experiment. After femoral catheterization, continuous intravenous lactated Ringer's solution was used to titrate central venous pressure in the range of 3 to $10 \mathrm{~mm}$ Hg. A $0.3-\mathrm{mL}$ blood sample was taken for blood gas analysis to maintain blood $\mathrm{pH}, \mathrm{PaCO}_{2}, \mathrm{PaO}_{2}$, potassium, calcium, and sodium in the normal range. The blood glucose was monitored with a glucose meter (FreeStyle Lite; Abbott Diabetes Care, Ontario, Canada) every 1 hour. If glucose

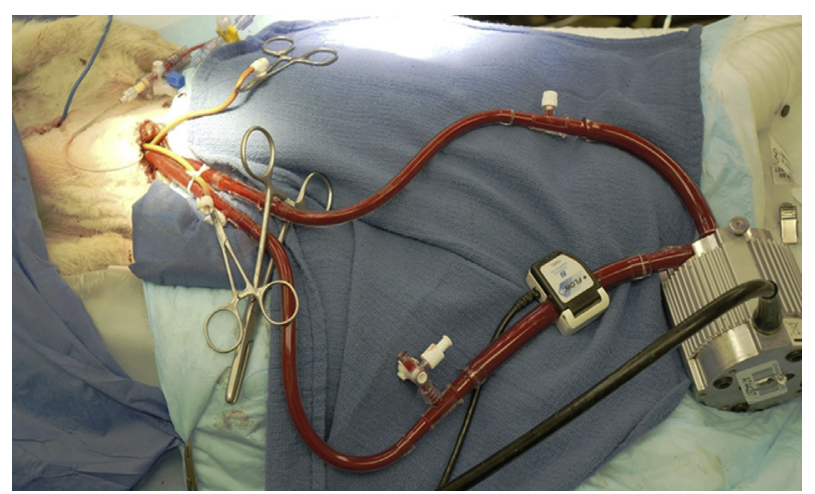

FIGURE 3. In vivo test of TAA DLC-based LVAD circuit. This neonate LVAD circuit consisted of the TAA DLC, a CentriMag blood pump, and connection tubing. was $<80 \mathrm{mg} / \mathrm{dL}, 50 \%$ dextrose was added into Ringer's solution for continuous intravenous supplement. Dobutamine $(3-5 \mu \mathrm{g} / \mathrm{kg} / \mathrm{min})$ was used to maintain mean arterial blood pressure $(\mathrm{mABP})>45 \mathrm{~mm} \mathrm{Hg}$.

Data collection and analysis. The femoral arterial/venous catheters and LV catheter were connected to transducers (Edwards Lifesciences, Irvine, Calif) for pressure monitoring. ABP, central venous pressure, and left ventricle pressure were monitored continuously during surgery via a Philips MP-50 monitor and continuously recorded by a data acquisition system (NI cDAQ-9172; National Instruments, Austin, Tex). The TS420 flowmeter also was connected to NI cDAQ-9172 to record the flow curve of main PA and aortic root. The aortic root diastolic backflow (regurgitation) was the integral area below 0 above flow curve in each cardiac cycle, where the forward flow (stroke volume) was integral area under flow curve above 0 . The aortic valve regurgitation was expressed by percentage of average negative flow area/average positive flow area. The aortic valve regurgitation with and without TAA DLC EIC in aortic valve were compared (Figure 4).

Blood was sampled for complete blood counts and plasma free hemoglobin measurement, immediately before LVAD pumping initiation and at sixth hour after LVAD termination. All data were expressed as mean \pm standard error. Differences between the time points were evaluated using the paired Student $t$ test or repeated-measures 1-way analysis of variance test.

\section{Necropsy}

After the experiment was finished, all lambs were euthanized with Beuthanasia-D (1 mL/10 lb; Schering-Plough, Union, NJ). During necropsy, the LV was opened from the apex incision, along left side of ventricular septum, across aortic valve to ascending aorta. The LV, aortic valve, and ascending aorta intima were visualized at necropsy for thrombosis and tissue damage. 

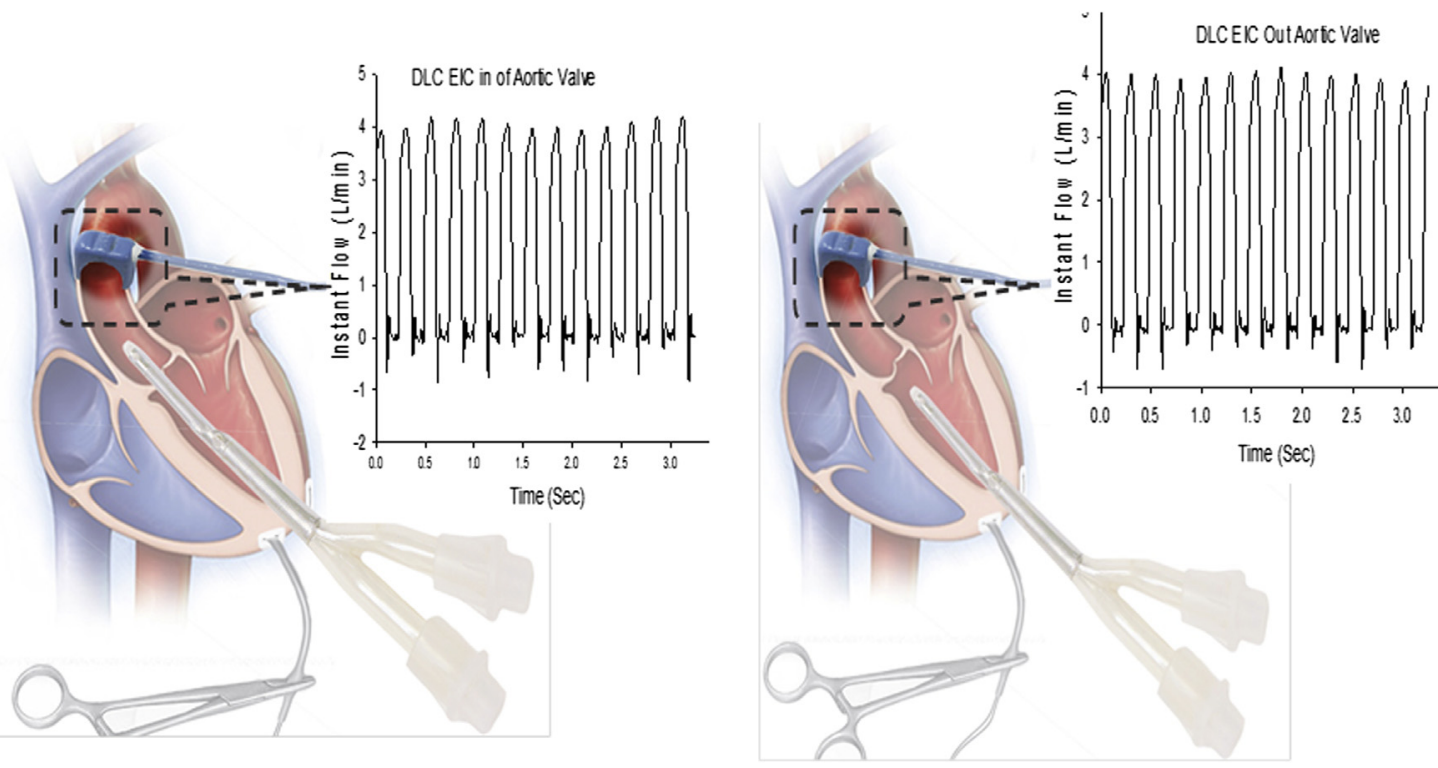

FIGURE 4. Evaluation of aortic valve regurgitation. A perivascular flow probe was placed on the ascending aorta to measure aortic valve regurgitation with and without the transapical-to-aorta DLC across the aortic valve. DLC, Double lumen cannula; EIC, extension infusion cannula.

\section{RESULTS}

The 18-Fr TAA DLC prototypes were fabricated successfully, bench tested in a mock circuit, and investigated in 6 neonate lambs.

\section{Bench Test}

The bench test generated a pressure flow curve of infusion lumen and drainage lumen. The 18-Fr DLC pumped up to $1.8 \mathrm{~L} / \mathrm{min}$ flow against $-63 \mathrm{~mm} \mathrm{Hg}$ drainage pressure and $145 \mathrm{~mm} \mathrm{Hg}$ infusion pressure. At a flow of $1.2 \mathrm{~L} / \mathrm{min}$, the drainage pressure was $-32 \mathrm{~mm} \mathrm{Hg}$, and infusion pressure was $71 \mathrm{~mm} \mathrm{Hg}$.

\section{In Vivo Test}

DLC insertion and deployment. The introducer catheter was inserted successfully from a $0.5-\mathrm{cm}$ incision on apex into $\mathrm{LV}$, crossing the aortic valve and ending in the ascending aorta, 1 to $1.5 \mathrm{~cm}$ beyond the valve. The pressure waveform was measured by the introducer catheter through the hole on the end, providing a clear indication of introducer catheter tip location. In all 6 lambs, the TAA DLCs were very smoothly deployed in proper position within 1 minute on first attempt.

Neonate lamb hemodynamic change with TAA DLCBased LVAD. The pumping flow was maintained at 1.2 to $1.3 \mathrm{l} / \mathrm{min}$. After LVAD pumping flow reached $1.2 \mathrm{~L} / \mathrm{min}$, the systolic arterial pressure decreased from $73 \pm 8$ to $68 \pm 9(P>.05)$, diastolic arterial pressure increased from $36 \pm 3$ to $49 \pm 6(P<.001)$, and mean arterial pressure increased from $50 \pm 4$ to $56 \pm 5(P<.05)$ (Table 1$)$, indicating decreased afterload and increased perfusion pressure. Left ventricle end diastolic pressure decreased from $12.7 \pm 1.0$ to $6.0 \pm 1.8 \mathrm{~mm} \mathrm{Hg}(P<.01)$ and remained stable, indicating decreased preload (Table 1). CO was increased significantly along 6 hours LVAD (Table 1).

TABLE 1. Hemodynamic change through 6-hour LVAD

\begin{tabular}{|c|c|c|c|c|c|c|c|c|}
\hline & Baseline & LVAD begin & LVAD $1 \mathrm{~h}$ & LVAD 2 h & LVAD $3 \mathrm{~h}$ & LVAD $4 \mathrm{~h}$ & LVAD 5 h & LVAD $6 \mathrm{~h}$ \\
\hline $\mathrm{sABP}, \mathrm{mm} \mathrm{Hg}$ & $73 \pm 8$ & $68 \pm 9$ & $66 \pm 9$ & $67 \pm 7$ & $74 \pm 7$ & $73 \pm 10$ & $77 \pm 7$ & $73 \pm 10$ \\
\hline $\mathrm{mABP}, \mathrm{mm} \mathrm{Hg}$ & $50 \pm 4$ & $56 \pm 6^{*}$ & $51 \pm 6$ & $50 \pm 5$ & $55 \pm 5$ & $54 \pm 2$ & $53 \pm 4$ & $52 \pm 6$ \\
\hline $\mathrm{dABP}, \mathrm{mm} \mathrm{Hg}$ & $36 \pm 3$ & $49 \pm 6 \dagger$ & $44 \pm 5^{*}$ & $41 \pm 6$ & $46 \pm 7 *$ & $43 \pm 5$ & $43 \pm 7$ & $40 \pm 8$ \\
\hline LVEDP, mm Hg & $12.7 \pm 1.0 \dagger$ & $6.0 \pm 1.8 \dagger$ & $6.0 \pm 1.8 \dagger$ & $6.3 \pm 1.4 \dagger$ & $5.1 \pm 1.9 \dagger$ & $6.0 \pm 1.8 \dagger$ & $7.4 \pm 1.3 \dagger$ & $6.8 \pm 2.1 \dagger$ \\
\hline $\mathrm{CVP}, \mathrm{mm} \mathrm{Hg}$ & $6.2 \pm 2.3$ & $6.2 \pm 2.3$ & $5.3 \pm 1.9$ & $6.0 \pm 2.4$ & $6.2 \pm 2.2$ & $5.5 \pm 2.7$ & $6.2 \pm 2.4$ & $6.2 \pm 2.8$ \\
\hline $\mathrm{HR}$, beats/min & $147 \pm 21$ & $155 \pm 18$ & $157 \pm 25$ & $155 \pm 22$ & $158 \pm 20$ & $165 \pm 23$ & $168 \pm 23$ & $167 \pm 21$ \\
\hline $\mathrm{CO}, \mathrm{L} / \mathrm{min}$ & $1.08 \pm 0.08$ & $1.23 \pm 0.09$ & $1.30 \pm 0.13$ & $1.36 \pm 0.11$ & $1.35 \pm 0.12$ & $1.41 \pm 0.10$ & $1.56 \pm 0.10^{*}$ & $1.57 \pm 0.05^{*}$ \\
\hline Assist flow, L/min & 0 & $1.22 \pm 0.07$ & $1.23 \pm 0.08$ & $1.24 \pm 0.07$ & $1.21 \pm 0.05$ & $1.22 \pm 0.06$ & $1.24 \pm 0.05$ & $1.29 \pm 0.08$ \\
\hline
\end{tabular}

$L A V D$, Left ventricular assist device; $s A B P$, systolic arterial blood pressure; $m A B P$, mean arterial blood pressure; $d A B P$, diastolic arterial blood pressure; $L V E D P$, left ventricular end diastolic pressure; $C V P$, central venous pressure; $H R$, heart rate; $C O$, cardiac output. Compared with baseline, $* 0.01<P<.05 ; \dagger P<.01$. 
TABLE 2. Hematologic change after 6-hour LVAD

\begin{tabular}{lcc}
\hline \multicolumn{1}{c}{ Value } & Baseline & After 6-h LVAD \\
\hline $\mathrm{Hb}, \mathrm{mg} / \mathrm{dL}$ & $9.0 \pm 1.3$ & $8.8 \pm 0.6$ \\
$\mathrm{fHb}, \mathrm{mg} / \mathrm{dL}$ & $10.0 \pm 4.6$ & $4.2 \pm 1.0^{*}$ \\
$\mathrm{Platelet}$ count, $10^{3} / \mu \mathrm{L}$ & $908.0 \pm 320.5$ & $800.3 \pm 344.7$ \\
Neutrophils $/ \mu \mathrm{L}$ & $4257.2 \pm 2002.7$ & $7568.7 \pm 3424.1^{*}$ \\
Lymphocytes $/ \mu \mathrm{L}$ & $1982.5 \pm 1087.8$ & $2043.0 \pm 458.5$ \\
\hline$L A V D$, Left ventricular assist device; $H b$, hemoglobin; $f H b$, free hemoglobin. $* P<.05$ \\
versus baseline.
\end{tabular}

Potential aortic valve regurgitation. Aortic valve regurgitation was increased from $2.4 \% \pm 0.6 \%$ without DLC inside aortic valve to $3.5 \% \pm 0.8 \%$ with DLC inside the aortic valve $(P<.05)$. Although this difference is statistically significant, the regurgitation is very small $(3.5 \%$ of $\mathrm{CO})$ with very limited clinical significance.

Hematology. After 6 hours of LV assist, free hemoglobin was decreased from $10 \pm 4.6$ to $4.2 \pm 1.0(P<.05)$. Blood hemoglobin, platelets and white blood cell count remained unchanged (Table 2).

Necropsy. No significant thrombus was found in pumps/ DLCs. No tissue damage was observed in LV, mitral valve/subvalve structure, aortic valve, and aorta. The DLC was placed back in the same position/depth of previous working position and was found to fit in LV-aortic valveascending aorta very well. The TAA DLC was in a good working position with EIC end 1 to $1.5 \mathrm{~cm}$ above aortic valve (Figure 5).

\section{DISCUSSION}

Our first TAA DLC-based LVAD prototypes were tested successfully in 6 neonate lambs, showing easy deployment, reliable performance, and no significant blood/tissue trauma in our 6-hour evaluation. LVADs have been

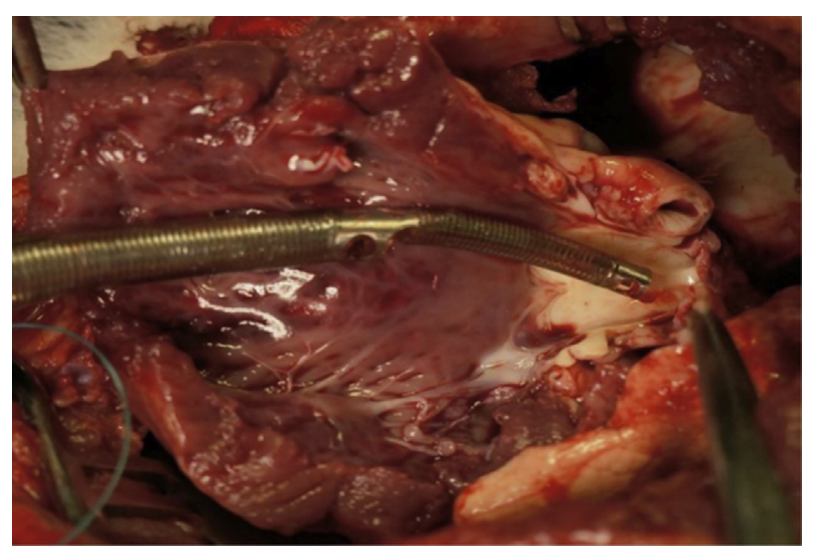

FIGURE 5. Necropsy results. There was no thrombus and no tissue/valves injury. The transapical-to-aorta double lumen cannula was in good working position. encouraged in pediatric patients because of their successful application in adult advanced heart failure. ${ }^{13-18}$ The main neonatal indications for a LVAD are congenital heart diseases and cardiomyopathies. ${ }^{3}$ These neonates require a LVAD to maintain survival with complicated heart anomaly and profound heart failure, because they are too small/sick for complex surgery/heart transplant, and there is a shortage of suitable donor hearts. Shortterm LVADs supply normal systemic perfusion, allowing the sick neonates to grow fast like normal neonates. At a larger body weight with better physical condition, complex surgical correction or heart transplant is more practical and less risky.

Currently, there are only 2 options for neonate LV support: (1) complicated and bulky VA ECMO, which requires not only high level anticoagulation but also continuous sedation with intubation/mechanical ventilation and (2) the EXCOR, approved by the Food and Drug Administration. ${ }^{2,19}$ Although the EXCOR is placed outside the body, chest closure may cause outflow graft kinking and creates coronary artery and heart compression in neonate. ${ }^{10}$ Several novel implantable rotary blood pumps are under development for pediatric LVAD with very promising progress. ${ }^{6,9}$ However, it is challenging to implant these small pumps into the neonate. Although some pumps are very small and can be inserted from apex, there may still not be enough retrosternal space for outflow graft, which may result in graft kinking and may cause heart and lung compression, potentially preventing chest closure. ${ }^{10}$

We aim to develop a less invasive and dependable LVAD system for neonate. The advantages of this DLC-based neonate LVAD are as follows:

1. The TAA DLC with 1-piece inlet and outlet construction omits outlet graft and avoids related kinking and heart/lung compression, theoretically providing reliable LVAD performance. This DLC fits completely inside the heart with no need of extra retrosternal space for accommodation, permitting chest closure. Therefore, this TAA DLC-based LVAD enables neonate recovery from anesthesia, which allows ambulation and normal oral feeding to promote recovery and growth of sick neonate.

2. Small left thoracotomy replaces large sternotomy. Most LVADs require sternotomy for installation. Some patients require repeat sternotomy for stage surgery, increasing the risk of bleeding. Our TAA DLC only requires a small left thoracotomy to expose heart apex, saving the sternotomy for future surgery.

3. No cardiopulmonary bypass is required for installation. Only a very small incision allows TAA DLC to be inserted from the apex into LV. The small introducer catheter with pressure monitoring accurately guides the DLC across aortic valve. By contrast, most of current LVAD 
implantations are complicated and often require cardiopulmonary bypass.

4. Flexible configuration: This TAA DLC provides a reliable connection between neonate and any available blood pump, establishing a dependable LVAD. This TAA DLC-based LVAD allows addition of a gas exchanger to elevate arterial $\mathrm{O}_{2}$ saturation in cyanotic heart diseases and lung complication.

In this in vivo neonate lambs test, the TAA DLC-based LVAD consistently decreased left ventricle end diastolic pressure during entire experiment, indicating decreased LV preload. The LVAD also immediately increased diastolic $\mathrm{ABP} / \mathrm{mABP}$ and decreased systolic $\mathrm{ABP}$, indicating improved myocardial perfusion and decreased LV afterload. No obvious blood damage was observed. Blood hemoglobin and platelet remained statistically unchanged. Plasma-free hemoglobin was not elevated and in a very low level at the end of the 6-hour LVAD test. The increased plasma-free hemoglobin before LVAD pumping was likely caused by catheterization and instrumentation.

This was a National Institutes of Health Small Business Innovation Research phase 1 proof-of-concept study. There are several limitations in this study. (1) The neonate used in this TAA DLC-based LVAD test was a normal lamb. A left heart failure model will represent a more accurate pathophysiology. (2) The neonate lambs used in this study were bigger than neonate human. Further study using a smaller lamb in the normal weight range of a neonate human is required to ensure that the TAA DLC will fit smaller anatomical dimensions without obstruction. (3) The size of the current TAA DLC prototype may be big enough to cause obstruction in a human neonatal patient. A smaller version of the TAA DLC will be designed to alleviate potential obstruction. (4) This is only a 6-hour in vivo prototype test. Survival study is required for longer term evaluation of performance, reliability and potential damage of aortic/ mitral valves. (5) For longer term usage, a DLC anchoring system is required. (6) In this in vivo test, dobutamine was used to maintain the mean $\mathrm{ABP}$, causing cardiac output elevation from 1.2 to $1.5 \mathrm{~L} / \mathrm{min}$. This low ABP may not need intervention by dobutamine as long as the right heart cardiac output was maintained at the baseline level. In the future, blood lactate should be measured to determine if this low baseline mABP with normal cardiac output can maintain whole body aerobic metabolism.

\section{CONCLUSIONS}

The TAA DLC-based neonate LVAD system was very easy to implant via a small left thoracotomy and efficiently unloaded the LV for 6 hours with no increase in free hemoglobin and no decrease in blood hemoglobin and platelet counts.

\section{Webcast}

You can watch a Webcast of this AATS meeting presentation by going to: http://webcast.aats.org/2016/Video/Wednesday/ 05-18-16_Ballroom_III_0741_Wang-800.mp4.

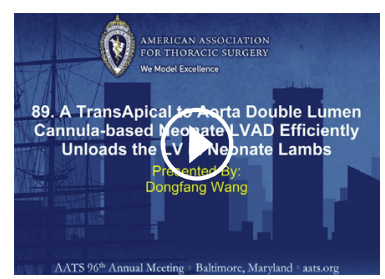

\section{Conflict of Interest Statement}

D.W. and J.B.Z. disclose co-ownership of W-Z Biotech, LLC. All other authors have nothing to disclose with regard to commercial support.

\section{References}

1. Duncan BW. Mechanical cardiac support in the young. Short-term support: ECMO. Semin Thorac Cardiovasc Surg Pediatr Card Surg Annu. 2006;9: $75-82$.

2. Food and Drug Administration. Berlin Heart EXCOR® Pediatric Ventricular Assist Device (VAD). HDE H100004. Vol. 2012 (2011). Available at: http:/ www.fda.gov/downloads/AdvisoryCommittees/CommitteesMeetingMaterials/ PediatricAdvisoryCommittee/UCM413734.pdf. Accessed September 2, 2016.

3. Morales DL, Almond CS, Jaquiss RD, Rosenthal DN, Naftel DC, Massicotte MP, et al. Bridging children of all sizes to cardiac transplantation: the initial multicenter North American experience with the Berlin Heart EXCOR ventricular assist device. J Heart Lung Transplant. 2011;30:1-8.

4. Fraser CD Jr, Jaquiss RD. The Berlin Heart EXCOR Pediatric ventricular assist device: history, North American experience, and future directions. Ann N Y Acad Sci. 2013;1291:96-105

5. Kirklin JK, Bennett Pearce F, Dabal RJ, Carlo WF. Mechanical circulatory support: strategies and outcomes in pediatric congenital heart disease. Semin Thorac Cardiovasc Surg Pediatr Card Surg Annu. 2014;17:62-8.

6. Wei X, Li T, Li S, Son HS, Sanchez PG, Niu S, et al. Pre-clinical evaluation of the infant Jarvik 2000 heart in a neonate piglet model. J Heart Lung Transplant. 2013:32:112-9.

7. Tamez D, LaRose JA, Shambaugh C, Chorpenning K, Soucy KG, Sobieski MA, et al. Early feasibility testing and engineering development of the transapical approach for the HeartWare MVAD ventricular assist system. ASAIO J. 2014 60:170-7.

8. Maul TM, Kocyildirim E, Johnson CA Jr, Daly AR, Olia SE, Woolley JR, et al. In vitro and in vivo performance evaluation of the second developmental version of the pediaflow pediatric ventricular assist device. Cardiovasc Eng Technol. 2011;2:253-62.

9. Baldwin JT, Borovetz HS, Duncan BW, Gartner MJ, Jarvik RK, Weiss WJ. The national heart, lung, and blood institute pediatric circulatory support program: a summary of the 5-year experience. Circulation. 2011;123: 1233-40.

10. Saeed D, Fukamachi K, Duncan BW. Intra-operative fitting study of the PediPump ventricular assist device. J Heart Lung Transplant. 2012;31: 109-10.

11. Fumoto H, Shiose A, Flick CR, Noble LD, Dudzinski DT, Casas F, et al. Shortterm in vivo performance of the Cleveland clinic PediPump left ventricular assist device. Artif Organs. 2014;38:374-82.

12. Weiss WJ, Carney EL, Clark JB, Peterson R, Cooper TK, Nifong TP, et al Chronic in vivo testing of the Penn State infant ventricular assist device. ASAIO J. 2012:58:65-72.

13. Grady KL, Naftel DC, Myers S, Dew MA, Weidner G, Sprtus JA, et al Change in health-related quality of life from before to after destination therapy mechanical circulatory support is similar for older and younger 
patients: analyses from INTERMACS. J Heart Lung Transplant. 2015;34: 213-21.

14. Jorde UP, Kushwaha SS, Tatooles AJ, Naka Y, Bhat G, Long JW, et al. Results of the destination therapy post-food and drug administration approval study with a continuous flow left ventricular assist device: a prospective study using the INTERMACS registry (Interagency Registry for Mechanically Assisted Circulatory Support). J Am Coll Cardiol. 2014;63:1751-7.

15. Holman WL, Naftel DC, Eckert CE, Kormos RL, Goldstein DJ, Kirklin JK. Durability of left ventricular assist devices: Interagency Registry for Mechanically Assisted Circulatory Support (INTERMACS) 2006 to 2011. J Thorac Cardiovasc Surg. 2013;146:437-41.

16. Menon AK, Gotzenich A, Sassmannshausen H, Haushofer M, Autschbach R, Spillner JW. Low stroke rate and few thrombo-embolic events after HeartMate II implantation under mild anticoagulation. Eur J Cardiothorac Surg. 2012;42: 319-23.

17. Kirklin JK, Naftel DC, Pagani FD, Kormos RL, Stevenson L, Miller M, et al. Long-term mechanical circulatory support (destination therapy): on track to compete with heart transplantation? J Thorac Cardiovasc Surg. 2012;144: 584-603.

18. Starling RC, Naka Y, Boyle AJ, Gonzalez-Stawinski G, John R, Jorde U, et al. Results of the post-U.S. Food and Drug Administration-approval study with a continuous flow left ventricular assist device as a bridge to heart transplantation: a prospective study using the INTERMACS (Interagency Registry for Mechanically Assisted Circulatory Support). J Am Coll Cardiol. 2011;57: 1890-8.

19. Fraser CD Jr, Jaquiss RD, Rosenthal DN, Humpl T, Canter CE, Blackstone EH, et al. Prospective trial of a pediatric ventricular assist device. N Engl J Med. 2012; 367:532-41.

Key Words: double lumen cannula, left ventricular assist device, neonate, apex to aorta, lamb

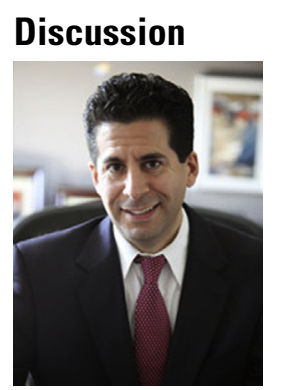

Dr D. Morales (Cincinnati, Ohio). I want to thank the Association for allowing me to be the discussant for this excellent proof of concept. The authors have introduced and tested a potential straightforward and minimally invasive approach to temporary ventricular assist device (VAD) support in the infant heart. This is a timely contribution, because like our adult colleagues, the pediatric VAD field is moving away from supporting INTERMACS (ie, Interagency Registry for Mechanically Assisted Circulatory Support) Status 1 patients, ie, cardiogenic shock, with durable devices, and we are now using more temporary VADs to resuscitate these patients and then moving them, hopefully, to recovery and explant or to long-term VAD support.

Also, these temporary devices are being used successfully by some as a bridge to transplant. The use of venoarterial extracorporeal membrane oxygenation for isolated heart failure is finally waning because its significant morbidities and inability to provide a good bridge to transplant is well documented.
The author's study demonstrates that their concept is an excellent one, with great potential. However, I have 2 questions.

Because the cannula going through the aortic valve is close to $4.5 \mathrm{~mm}$, which would fill the majority of a neonate's aortic valve cross-sectional area, do the authors feel that this will cause obstruction of native ejection? This will be important since the catheter will hopefully be deployed in patients with a high chance for recovery.

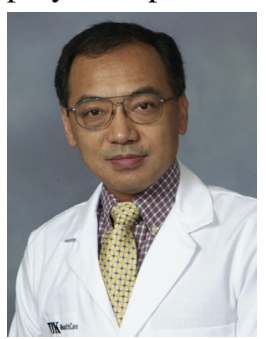

Dr Wang (Lexington, Ky). In our first 3 pilot animals, we experienced difficulties with cannula tip location identification, resulting in penetration of left atrium. In the current study, a lot of effort was spent on developing an easy procedure to place the cannula smoothly. Therefore, we have not very carefully evaluated the obstruction issue in this study. However, in the future, we will pay great attention to this potential issue. We will have one pressure sensor in the left ventricle and second one above the aortic valve to measure the pressure gradient for assessing aortic valve obstruction.

Dr Morales. I think the beautiful thing about the catheter is you can make multiple sizes, so perhaps you can use smaller ones depending on the aortic valve size.

Dr Wang. Yes, we can make multiple sizes of the catheter, encompassing small baby through adult size.

Dr Morales. The second question is: What is limiting the flow to less than $1.8 \mathrm{~L} / \mathrm{min}$ ? Is this limitation only inflow pressure, or is outflow pressure an issue?

Regarding the inflow, can you make the inflow orifice larger? Also your apical cannula, is only $6 \mathrm{~mm}$ so one can imagine in an infant's heart, you could probably use a7 to $8 \mathrm{~mm}$ cannula to improve your inflow as well.

Are you planning to make several different catheter sizes?

Dr Wang. Yes, we can and will make the inlet orifice larger. We also plan to make multiple inlet orifices to prevent potential inlet obstruction. We are also going to have several additional sizes for medium children up to a fullsize adult. The double lumen cannula in this study was specifically designed for a neonate.

Dr Morales. And I congratulate the authors because the introduction of this simple and elegant cannula that can be adapted really to any centrifugal pump that a program might have and that is quickly deployable for temporary support makes its potential to impact our clinical practice significant. Thank you. 